\title{
Computer Network Quality of Service Optimization Method under the E-commerce
}

\author{
Yulong Zuo \\ Feixian College, Linyi University, Linyi, 273400, China
}

Keywords: E-commerce. Computer Network. Quality of Service

\begin{abstract}
With the modern network technology rapid development, modern for the dependence of the information resources is growing; therefore, enterprise demand of computer network service under the e-commerce is continuously increase. However, now, it's dispersed and disorder about the distribution of the e-commerce information resources, and difficult to provide quality computer network service timely and effectively. Hence, optimizing computer network quality of service under the e-commerce has the extremely significance to improve the effectiveness of information. This article summarizes the computer network service under the e-commerce; analyzes the advantage of computer network service; introduces the types of computer network services under e-commerce, and influence of computer network services for e-commerce, and puts forward further computer network quality of service optimization method under the e-commerce.
\end{abstract}

\section{Introduction}

In recent years, e-commerce has been got attention to the communities, and developed rapidly. However, at present, there are some constraints of developing e-commerce; the main reason is that the function of e-commerce system is too single; computer network can only provide the service of basic net browse and shopping goods for customers. In fact, quality of computer network service is the important links in e-commerce. Therefore, as the network service technology development, we should optimize the quality of service of computer network, and adapt to the rapid development of e-commerce.

\section{Computer network service summarize under the e-commerce}

E-commerce refers to modern electronic technology, especially a series of service quality to improve activities of the computer network implementation. It's the products of the computer network and the popularization computer; also is a form of business activities in current network times, it represents the mainstream of business operation and development. The essence of e-commerce is social information. So, its emergence has represented one of the important trends of social development under the current information age, which leads to the major changes brought by society; it's a very big driver for the development of the society and economic. Computer network service is a socialization activity, which is mainly spread and release around information organization; provides social information and manages the business, and implements the decision-making. Computer network service involves provider, carrier and demander; the characteristic of it is retrieval specific information that service objects needs from the information database, and then, provides needs to service objects. In development of social information age, the development of electronic and commerce and computer network demands change the traditional network service form, and expand service areas; improve the new e-commerce service mode. This proves that computer network service under the e-commerce can also accelerate the process of enterprise business; reduces the commercial cost; and creates a better business development opportunities. 


\section{The Outstanding advantages of computer network services}

In order to better understand the advantages of computer network service, the most important is to understand the application of tight-binding type and application of loosely-binding completely. Specifically, the previous systems of traditional sense mainly rely on the system development workers, and are told how to interact with other systems in advance, and can share information or complete the task by cooperating. This model has great advantage, for example, due to the system understands each other, and it's more convenient to implement security checks. However, this model still has considerable limitation; the system must be set how to interact with other systems in advance. Therefore, the existing system must be difficult to interact with new system, besides, developer still need to spend much time to consider the relationship between various systems as well as the interaction issues. Later system can solve some existing problems of the previous. Due to research workers neither need to think about how to find other applications nor define the rules of interaction with other applications in advance, and the most advantage of loosely-bind application system is to promote application system's flexibility and operability, that is to say, loosely-bind application system would be easier. And it's difficult for traditional e-commerce to provide about this feature. Computer network service is the outstanding representative of loosely-bind application, and its most advantage is able to publish and find service dynamism. After adding new applications, now, other applications of the existing can also find and use new application, and provide relevant resolutions easily, and it don't need to be modified. It would save a lot of cost development for those who provide e-commerce service enterprises.

\section{Computer network service type under e-commerce}

1). Government provides public e-commerce computer network information service. This part mainly includes relevant information of government agency regularly or irregularly issue publicly, such as policies and regulations, government procurement bidding, national economy data and economic statistic. This kind of information belongs to the main part of the information service under e-commerce, service object will not be restriction, and how much information public is also the important symbol about whether e-commerce popularize in this region. So, public information service is extremely important.

2). Computer network information service share by inner-enterprise and between inter-enterprises. This part of sharing information service mainly can be divided into inner-enterprise and between inter-enterprises' all kinds of information services. What computer network service object shared by inner-enterprise is relevant department or agency, while, between inter-enterprises is supplier; belongs to the strategic partnership. Product development, production planning, quality and sales information should be shared. All services shall be authorized by managers, and shared through network. Various increments information services are provided by third party professional computer network information service intermediary agencies. Due to the public information is too messy, the third party professional computer network information service intermediary agencies have opportunity to provide various increments. Increment information mainly includes the information search, analysis and prediction, such as price and performance of commodity, the current stock market and trend of national economy in future period. Due to this kind of service has considerable value, users are required to pay the corresponding cost. It's not enough for enterprise only rely on sharing information and public information between enterprises under the rapid development e-commerce. In order to get more timely and accurate information, you can put information outsourcing to information consulting firm; help company reduce the cost of gathering information as much as possible, and promote economic benefit on the maximum. 


\section{The influence of computer network service for e-commerce}

We analyze from a case about traditional sense e-commerce model. PRM as a professional pencil wholesale enterprise, a major goal about market operation is to find a supplier who offer the least bidding price, and meet the main demand of downstream retail enterprise. This is a typical supply chain under e-commerce. During operation, upstream supply is the main lifeline of PRM, so, PRM must grasp bidding accurately offered by suppliers in every moment, whether supplier have available inventory immediately, product quality and delivery time provided by supplier. In traditional e-commerce, PRM market operation is likely to use the search engine such as Google, Alta Vista, and may get thousands of entries. Through browsing carefully, you can find only few enterprises are real pencil suppliers, browsing each supply enterprise website carefully, and make a choice until query the bidding, inventory, and delivery time of the supplier. For PRM, this work is really too big, and another important question is that even the best search engine can only cover part of supply enterprise. Therefore, to implement computer network service under e-commerce is very important. Today, with the help of computer network service, PRM would find their work more easily. If all the pencil suppliers that participate in e-commerce are provided e-commerce platform based on computer network service, then, PRM only need to login in special website, and can inquire all enterprises that provide pencil; and then login in supplier website, you can clearly query the bidding, quality, inventory of the goods. More convenient, there needn't any people involved in whole process, because of the format conveyed by message in computer network service has already been negotiated, and can be completed automatically by computer. It's worth noting after querying bidding; system can compare automatically; find the least bidding supplier, and issue order. At the same, computer system can track the order continually until the goods arrive. It's seems that stocking with goods in PRM is almost entirely without people involving through computer network under the e-commerce. Today, staffs in PRM can feel the power of the e-commerce. In fact, this case is a way about Web Service technology applied in traditional e-commerce. Only further explore, you can find more applications in B2B, B2C, and even form a new e-commerce transactions.

\section{Optimize the method of computer network service quality under e-commerce further}

1). Analysis the computer network users' demand. Meeting the needs of users on the maximum is the ultimate goal of the computer network information service, therefore, before providing computer network information service, we should analysis users' demand effectively, and have a clear understanding about all kinds of information type that computer users need; provide way, and provide technology type, then; implement the relevant computer information service. Computer network is an important content under modern e-commerce, one part of network service contents belongs to confidential information for users, therefore, implementing the service through computer network, you not only ensure information, but also reduce the redundancy and the sending all kinds of unnecessary information as much as possible.

2). Expand information service subject. Today, computer information resources has become more and more important in modern economic life, it not only the provider of computer information resource provide and issue continually, but also other social organizations and enterprises use various methods to develop its own outstanding advantages, and enter the computer information service field. For this purpose, when you apply theory of diversification to research computer network service subject under e-commerce, but it neither mean deny the dominant effects of the government in public information network development, nor need to rely on marketization force to obtain and adjust allocation of information resources. The public is the main object of the computer network information, while, enterprise is the top priority in computer network objects, its demand is varied, and what it needed service mode is also difficult. Diversify subject of different organizational mobilization ability and advantages not only offers personalized computer network information service for masses of users who have different preferences; promote computer network service 
quality, but also better fills in deficiencies about management of government in computer network information resource, so as to makes up the defects of the current market mechanism.

3). Strive for provide integrated computer network service. Integrated information is for a specific goal, or is a concept when facing a particular task and implements organization management for computer network information, so that diversify information could organically mix, and be used optimization. The integrated service of computer network information is not a mechanically make up for information business area, but provides a new modern service concept. This is a big leap in computer network service distribution. The integrated service of information can only work under computer network, also take the computer network as essential condition. What the computer network information service range of the enterprise needs are production, market and policies. Once you put the above all information into a comprehensive integration, you can provide a better one-stop service for enterprise, and promote the resource utilization of computer network information.

\section{Conclusion}

In all, under modern e-commerce, as the computer network service demand increase, it will promote the continuous development of e-commerce information service. Therefore, we must recognize that now the deficiency of e-commerce computer network service in our country; put forward practical and effective measures; and promote comprehensive optimization of computer network service quality of e-commerce in our country.

\section{References}

[1] Yincheng Xie: Web-services platform and enterprise e-commerce strategy, Jiangsu Commercial Forum, 2006(8).

[2] Junfeng Li: Network command applied in computer network engineering, Journal of HuBei Three Gorges Vocational and Technical College, 2009(1).

[3] Yu Jing, Fang Ming: Computer network security stategy, Science and Technology Information, 2009(25).

[4] Jialin Tang: The influence of e-commerce service quality to consumers' behavior, Industrial and Science Tribune, 2012(24). 